\title{
Creative solutions to making the technology work: three case studies of dyslexic writers in higher education
}

\author{
Geraldine A. Price* \\ University of Southampton, UK
}

\begin{abstract}
Research into the behaviours manifested by the dyslexic condition has often focused upon younger dyslexic pupils and the lower-order skill difficulty in decoding and encoding. A surge in interest in the writing process has shifted the focus to higher-order skills, and a growing body of research is emerging within the higher education context (Hughes \& Suritsky, 1994; McNaughton et al., 1997; Hatcher, 2001; Singleton \& Aisbett, 2001; Farmer et al., 2002). Students are expected to be 'expert' writers, and the mark of a good student is the ability to use writing as a tool for thinking. Drawing upon data from semi-structured interviews with undergraduate and postgraduate dyslexic students and their real-time writing logs, three case studies are presented and used to explore creative ways of using technology to manage dyslexia. The students demonstrate how they use different types of software to overcome writing anxiety, 'fear of the blank page' syndrome and issues of plagiarism. The experiences of the students within the case studies demonstrate that often simple software can provide the best solutions, and that students combine features from software programs in creative ways to compensate for weaknesses in their cognitive profile.
\end{abstract}

\section{Introduction}

In the United Kingdom, removing barriers to achievement is the most recent government educational initiative (DfES, 2004) and encapsulates the growing support for inclusive education that has been strengthened by powerful disability discrimination legislation (HMSO, 2001). In pursuit of the ideological vision of inclusion, higher education (HE) institutions have had to re-think policy in relation to promoting equality of student experience while at the same time responding to the growing diversity of the student population. This has led to an upsurge in interest in the teaching and learning environment, coupled with e-learning initiatives. The growth in assistive technology support services, financial support for students'

\footnotetext{
*School of Education, University of Southampton, Highfield, Southampton SO17 1BJ, UK. Email: gap@soton.ac.uk
} 
technology needs through the Disabled Students' Allowance and a more widespread acceptance of technology use in society are all factors that have generated change. While Raskind and Higgins (2003, p. 175) are convinced that the introduction of assistive technology for students with learning difficulties has acted 'as a catalyst' for this change, investigation into its use and application is vital in helping to provide future solutions for policy-makers, educationalists and users. However, the students' voice is an important dimension in these enquiries, and exploration of their creative use of technology may inform pedagogy.

Over the past 30 years the driving pedagogy in special education has remained unchanged. It relies upon a Vygotskian approach to teaching and learning whereby the development of metacognition through scaffolded teaching, modelling, structured learning and the individualisation of learning outcomes has been strongly advocated (Vygotsky, 1978). It is comforting for those in the special education needs field that these approaches have now been adopted more generally and are frequently part of the rubric of DfES directives. The Vygotskian concept of scaffolding, whereby guidance and participation are at the heart of the experience, has been adopted in the teaching of adult learners, and the notion of a 'means of assisting' is not new (Tharp \& Gallimore, 1991, p. 42). Indeed, assistive technology could be viewed as a technological scaffold. With all scaffolding techniques, however, it needs to be evaluated so that the implementation of its use is appropriate and effective. The study reported here examines the way that three dyslexic students have made use of assistive technology.

\section{The impact of dyslexia on the writing process in higher education}

There has been a proliferation of definitions of dyslexia over the past 100 years (Hinshelwood, 1917; Critchley \& Critchley, 1978; Miles, 1982; Frith, 1995; British Psychological Society, 1999; Reid, 2003). Many of these definitions have related to young children and basic literacy difficulties, and therefore have less relevance for HE. The definition used in the study reported here is both descriptive of the dyslexic profile and rooted in current research of causal factors:

Developmental dyslexia is a severe difficulty with the written form of language independent of intellectual, cultural and emotional causation [...] The difficulty is a cognitive one affecting those language skills associated with the written form, particularly visual, verbal coding, short-term memory, order perception and sequencing. (Thomson \& Watkins, 1998, p. 3)

The notion that dyslexic learners only have difficulties with reading and spelling has been dispelled in the past 10 years by the growth in research into the impact of dyslexia in HE. The cognitive deficits associated with dyslexia have a considerable impact upon the management of the writing process. This has great significance when one considers that professional and academic success in today's society is dependent upon the ability to communicate effectively in writing.

The cognitive resources used in the writing process are considerable, and memory capacity and storage are often overloaded by competing, simultaneous operations. 
The ability to synthesise information is one of the essential skills required by HE students. The notion of 'shaping at the point of utterance' (Britton, 1983) is an inherent feature of academic writing in HE. On the one hand students are expected to re-shape or 'transform' information from a variety of sources (Bereiter \& Scardamalia, 1987); to wrestle with the ideas and to develop personal constructs and synthesise information from study. On the other hand, this cognitive network is overlaid with the conventions of writing: knowledge of language and linguistic structures such as sentence and paragraph construction; genre; syntax and semantics. Some students seem better equipped than others and seem to tackle written assignments in their stride with a minimum of conscious 'executive control' of working memory (Baddeley, 1990). Not only do they have the ability to move from the simple 'knowledge-telling' (Bereiter \& Scardamalia, 1987) or descriptive model of written composition to a 'knowledge-transforming' or re-shaping model, but they can do so within harsh schedules, demonstrating automaticity and fluency of operation. The way in which the dyslexic writer processes language, the speed at which this is performed and the way in which executive controls in working memory are used may make a difference to performance and production.

The paradox of dyslexic writers lies in the fact that they appear to function on one level as novice writers but have to operate within a context of 'knowledge-transformers' (i.e. expert writers). The question thus arises as to how these writers cope with this phenomenon, given that their cognitive profile results in a drop in performance when they are required to simultaneously process at different levels. They need to be able to manage and hold in memory the overall plan while working on specific parts of the essay - the macro (overall plan and structure) and micro (paragraph and sentence) levels of text construction. This multi-tasking ability puts pressure upon the resources of the working memory. One way in which non-dyslexic, expert writers cope is to ensure that the low-level operations of writing-reading, spelling, handwriting, sentence construction, and so on - are on automatic pilot, and that these features do not, therefore, take up precious working memory space when constructing and structuring essays.

Three dyslexic undergraduate and postgraduate students provide the basis of the phenomenological study reported here. Semi-structured interviews together with realtime sampling of written work provided information about the individual writing behaviours. The discrete elements of the writing process were analysed, and the students' difficulties within this process were noted. The elements of the process explored were:

- collecting information;

- planning, both before and during written production;

- drafting/translating;

- editing; and

- proof-reading and neat copy.

Most of the students adopted both intuitive and taught strategies to compensate for organisational problems and weaknesses in working memory capacity. A mixture of technological and traditional methods was chosen by the students to help compensate for cognitive deficits. 


\section{The study}

This research study brought together findings in education and cognitive psychology and necessarily utilised a mixed methodological approach, which incorporated both quantitative and qualitative data. The original research study, of which this paper describes just one of the aspects of the findings, set out to explore the effect of the individual differences of the dyslexic cognitive profile on the writing process. As a result, psychometric data were examined to ascertain the individual cognitive profile of each student. A psychometric test is a method of measuring an individual's performance in relation to the whole population. The data were derived from psychological assessments, mainly the Wechsler Adult Intelligence Tests, and a variety of norm-referenced spelling and reading tests. These data therefore provided objective and standardised measures of performance. Norm-referenced data have been recorded as percentile scores for the purposes of this paper because they demonstrate in a simple statistical manner the performance levels of each student and place the level of functioning in the context of the whole population. Thus, the 50th percentile represents average performance within a given population. To give an example of this system: the 14th percentile indicates that $86 \%$ of the population can perform more effectively. This type of data represented a part of the picture of the dyslexic writer and provided information about functional literacy and the way in which the writer processed information in relation to working memory capacity.

As a social scientist, the researcher adopted an interpretive approach to try to understand the difficulties and differences experienced by the dyslexic student in their academic writing. It was felt that it was even more vital at this current time to ensure that the student voice was not overlooked. The centrality of the dyslexic students' voice therefore provided evidence to question many of the 'taken-for-granted assumptions' (Cohen and Manion, 1998, p. 30) and preconceptions of academic writing in the HE sector. Through the students' voice, it was hoped to bring meaning to the dyslexic writing experience. These data were collected mainly by structured interviews, which were based upon the ebb and flow of the writing process-indeed, the way in which individual, dyslexic students organise and manage the writing experience as part of their academic studies.

In order to allay criticisms of 'opportunist eclecticism' of mixed methodological approaches (Bullock et al., 1992), rich, in-depth data on each student were collected. The individual's speed of processing language information both on input (when reading course texts, online notes, etc.) and output (when composing or translating ideas onto paper/screen) was measured mainly by the standardised assessment tasks already mentioned. The data consisted of the following:

- Reading and spelling performance in terms of accuracy, fluency and speed.

- Analysis of writing speed (words per minute) compared with typical writing speeds for the HE student population. This would not only provide information about the student's processing speed on output, but would also give indications of memory capacity and memory storage when examined in relation to the psychometric data. 
- A writing log: real-time sampling data for statistical analysis of the writing process.

- Semi-structured interviews: partly to ascertain compensatory strategies during writing.

- Hard copy of draft written assignment work.

- Hard copy of the final assignment.

- Marks/grades received for the written work.

Each student was given a pack containing an audio-tape recorder, a random bleep tape and pre-printed record sheets, which contained the following writing categories:

WN: Writing Notes

CO: Changing Outline

WO: Writing Outline

CT: Changing Text

WT: Writing Text

RT: Reading Own Text
TC: Thinking about content

RR: Reading Reference Books, etc.

TW: Deciding on Wording

RO: Reading Outline

NN: Making Neat Copy

XX: Unrelated

The real-time sampling procedure involved asking each student to circle the activity on the record sheet that best described what was being done when a bleep sounded on the audio-tape. The electronic bleeps, which the students listened to on the audiotape, occurred at random intervals of between 30 and 150 seconds with a mean of 93 seconds. The students were given training in how to use the record sheets before they started. They were shown a video of someone going about a writing task. The training video was stopped at different writing activities, and the students were asked to decide which activity this related to on the record sheet. In this way, discussion about aspects of writing occurred and strengthened the reliability of the writing logs because, through the discussion, all the students had a shared understanding of the terminology so that there was greater accuracy in recording. This method of gathering realtime sampling data for statistical analysis replicates the method used by Torrance and Jeffrey (1999).

\section{The case studies: three student experiences}

The use of assistive technology as a scaffold to learning is a topic that has captured the interest of researchers in recent years, although the number of studies remains low (Yelland \& Masters, 2005). The Computer Supported International Learning Environment developed by Scardamalia and Bereiter (1996) has been adapted to investigate computer environments and software to support students (Oshima \& Oshima, 1999). Much of this research explores the interaction between teachers, students and software within a social-constructivist paradigm. While more dyslexic students are aware of the range and uses of word processing, voice-activated and mapping software, the way in which they use the programs to support their individual cognitive profile is often creative. This is reflected in the three chosen case studies. 
The student in the first case study uses mapping software in a physical way to manage her writing and overcome anxiety. The second student demonstrates that using the advanced facilities of some simple software can help overcome the blank page syndrome. The student in the third case study explores a method of using technology to overcome the fear of plagiarism.

\section{Student A: using technology to manage the process}

Student A was a severely dyslexic student who failed her first year of Medicine. As a result of this failure, her academic tutors advised her that she ought to seek advice from Dyslexia Support Services. Since the identification of her dyslexia, she has received academic skills tuition from a specialist tutor. She was taught many strategies to enable her to cope with the rigorous demands of her chosen course of study. Her dyslexic profile is typical of the experiences related by dyslexic students who have not been identified until they reached HE (Riddick et al., 1999; McLoughlin, 2001):

- Never seemed to obtain results that reflected time and effort.

- Reflective learner who lacked self-confidence in academic skills.

- Oral sentence structure lacked sequential fluency.

- Could not process different types of information simultaneously (multi-tasking).

Table 1 provides an overview of the strengths and modes of working that were adopted by student $\mathrm{A}$.

Table 1. Summary of strengths, technology and modal preferences of Student A

\begin{tabular}{|c|c|c|}
\hline Preferred working styles & Strategies Adopted & Technology Use \\
\hline $\begin{array}{l}\text { Needs global picture to activate } \\
\text { working; }\end{array}$ & $\begin{array}{l}\text { Worked on small chunks of } \\
\text { text; } \\
\text { - Alternated between } \\
\text { drafting \& editing; } \\
\text { - Physical method of } \\
\text { planning - compensates for } \\
\text { organisational difficulties, } \\
\text { sequencing, moving } \\
\text { between macro \& micro } \\
\text { operations; }\end{array}$ & $\begin{array}{l}\text { Inspiration Software: } \\
\text { - flow chart work schedule } \\
\text { - content \& rhetoric planning } \\
\text { - able to control shift between } \\
\text { macro \& micro operations of } \\
\text { the writing process }\end{array}$ \\
\hline $\begin{array}{l}\text { VERY unsure of language use; } \\
\text { - Plagiarism issues - checks \& } \\
\text { re-checks language; } \\
\text { - Worked on one aspect of the } \\
\text { writing process at a time; } \\
\text { - Used auditory strength to edit } \\
\text { work; } \\
\text { - Physical strategy - } \\
\text { kinaesthetic worker }\end{array}$ & $\begin{array}{l}\text { Weak visual memory skills } \\
\text { by-passed by technology use } \\
\text { Text stress managed by } \\
\text { coloured acetates }\end{array}$ & $\begin{array}{l}\text { Speech Recognition Software: } \\
\text { - micro level drafting at } \\
\text { sentence construction } \\
\text { - editing work } \\
\text { Talking Thesaurus: } \\
\text { - taps into semantic strengths }\end{array}$ \\
\hline
\end{tabular}


Examination of the cognitive profile of student A suggested that she would experience difficulties in the writing process because her low-level skill performance was not fluent:

- Spelling: 14th percentile (where the 50th percentile represents the average). The 14 th percentile indicates that $86 \%$ of the population can perform more effectively.

- Single-word reading: 47 th percentile (her performance on prose reading was considerably lower).

- Written production: 15 words per minute with a $6 \%$ error rate.

Added to this, her language retrieval and structuring and her speed of information processing placed her in the second percentile, which meant that $98 \%$ of the population were better equipped to cope with language retrieval than Student A. This placed her under great pressure during the writing process. She spent an incredible $49.27 \%$ of the total time taken to write her assignment on drafting her work. Thus, essay writing became a source of anxiety:

I did my first essay and I did really badly because I didn't know how they wanted it to be written or I didn't know the language and things like that. (Extract from semi-structured interview with Student A)

Student A needed to find ways to manage the whole process. This would enable her to juggle all the planning and decision-making aspects of this recursive process while at the same time enabling her to perform the parts of the process more efficiently so that she could cut down on the time she took to produce essays of a good standard.

Her cognitive style was such that she needed to get the global picture before she could begin any assignment: before she could tackle the initial reading, note-making, drafting and editing. In her interview she explained how she used technology to overcome these complications. She now always uses a computer and no longer puts her own text into long-hand, because: 'I would struggle to read my own handwriting'. She used a combination of software to support her needs:

- Mind-mapping software: in a creative manner to support her individual cognitive style.

- Text-to-speech software: to support her hesitant reading skills and to develop critical reading skills.

- Talking spelling checker and thesaurus: to by-pass her weak visual memory skills and to tap into her auditory strength and ensure accuracy and efficiency.

- Coloured acetates and individualised screen colour backgrounds: to reduce visual stress when reading.

She found a way of making technology work for her by ensuring that she did not overload her working memory capacity, yet was able to keep the global picture of her assignment constantly in view, thus helping her to manipulate and manage different components. She used Inspiration, a mind-mapping device, in a 
traditional way to support essay planning and paragraph production, but also used it in a physical manner to monitor the organisation of the different parts of the writing process.

Student A's use of Inspiration ${ }^{\circledR}$ demonstrates how software can be adapted to individual needs. Student A commented:

I find it ... 'cause I get really confused trying to work out ... like ... the written one I did for my tutorial I get all confused, so I like just using it, so that I do sort of like a flow [chart] so I know where I'm going.

A translation of the above:

I get really confused trying to work out and organise what I want to say. I had to do a written assignment for a tutorial and I got all confused. So I started using Inspiration (electronic mind mapping tool). I did a flow chart of my outline ideas to help me to sequence things so that I know where I am going.

For student A, the software became a technological scaffold, which operated on various levels to provide support for weaknesses in her cognitive profile. The combination of traditional and creative modes of using the software demonstrates its duality of use. Firstly, she worked on screen using the software as a prompt for the generation of initial ideas. At the next stage she re-arranged the 'ideas bubbles' into a numbered flow chart with bullet-point reminders. Once this was completed she printed out a hard copy of the flow chart, which provided her with the basis for planning operations (macro-level operations).

In the past Student $\mathrm{A}$ had found the organisation and management of all her notes (both from lectures and research reading) problematic. She was aware that she wasted time trying to locate a piece of information, which she needed when she was drafting her work. She knew she had read something somewhere and made a note, but the retrieval of this information became 'a nightmare'. Technology came to her aid. She took each individual idea bubble, enlarged it and printed it out on a separate A4 sheet. She then used this as a marker. Thus, she was able to work upon small chunks of the essay, almost treating each section as a mini-essay. She then went about collecting all the information she needed for each section. All her notes, quotations and scanned book chapters that were relevant to this section were physically placed underneath this marker. Instead of her room being strewn with papers in a haphazard way, she was able to categorise the information physically, yet at the same time not overload her working memory capacity. She then worked exclusively on one of the sections, sequencing her thoughts by the use of the prompts on the front marker. In this way, she was able to compensate for her difficulties in information processing and working memory capacity. Putting the sections together then became a more manageable process: she only had to work on formulating linking sentences instead of having to think about what had been said in a section, what she was moving on to and how she could retrieve suitable language to communicate these ideas to others. The sections of the flow-chart (Figure 1) became the physical hooks to provide a scaffolded structure for written communication. 


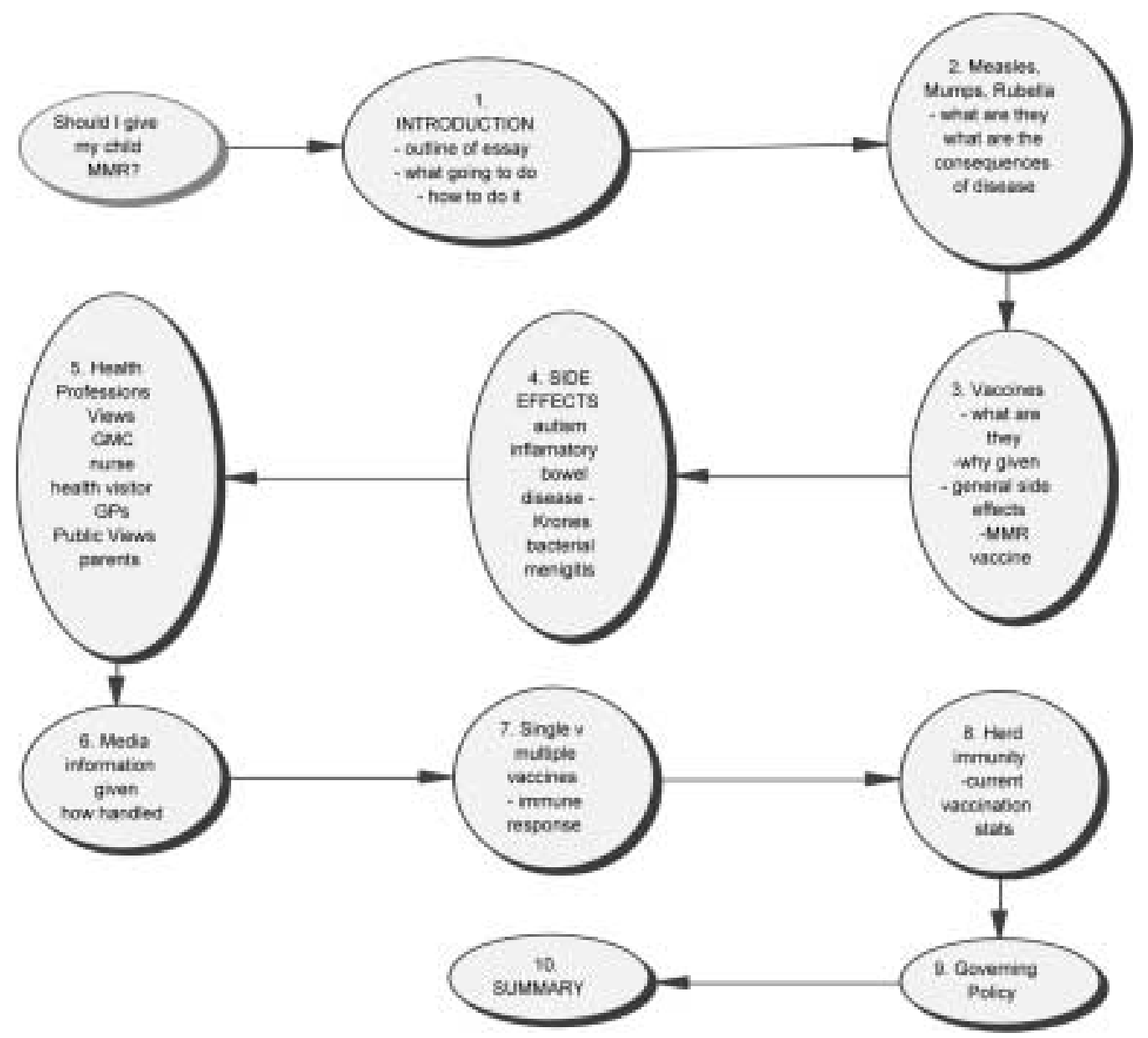

Figure 1. Example of Student A's planning strategy

Student B: software support for the 'blank page syndrome'

Student B was in his third and final year of a Mechanical Engineering degree, having obtained an engineering scholarship. He was an older student, aged 24 years at the time of this study, and entered HE having successfully completed his apprenticeship and ONC/B.Tech. qualifications. He was a competitive young man who was highly motivated to succeed. His experiences in the engineering field meant that he adopted a pragmatic approach to many situations and always wished to find practical solutions to his problems. Student B's writing behaviour was, to some extent, shaped by his perception of himself as a writer. He was aware of his own short-comings and was keen to learn new techniques to help him reach his goal of an Upper Second or First degree. He saw his problems as: 
- Grades that did not reflect his depth of knowledge and understanding.

- Inappropriate ways of working, which led to his spending much longer than his peers on written communication.

- Written work that lacked structure.

- Difficulty 'keeping all the balls (of the essay) in the air at the same time' (i.e. multitasking problems).

Table 2 provides an overview of the strengths and modes of working that were adopted by Student B. Examination of Student B's cognitive profile suggested that he would experience difficulties in the writing process because his low-level skill performance was not fluent:

Table 2. Summary of strengths, technology and modal preferences of Student B

\begin{tabular}{ll}
\hline Preferred working styles & Strategies adopted \\
\hline $\begin{array}{ll}\text { Needs global picture to } & \text { Worked on small chunks of } \\
\text { activate working; } & \text { text; }\end{array}$
\end{tabular}

VERY highly organised and like to take control of the whole process;

Competent computer user who realised that he could use the facilities to his advantage to enable him to be more efficient;

Highly organised filing systems within his folders on his laptop; Used auditory strength to edit work.
Alternated between drafting and editing;

Weak visual memory skills by-passed by technology use; Was made aware of the strategies which would provide greater efficiency in his organisational framework and constantly evaluated and refined these strategies thus developing a metacognitive approach to the writing process.
Technology use

Blackboard information:

- used this type of course information so that he could manipulate selections electronically to save himself time and to cut down on inaccuracies in spelling.

Word processing software:

- for the planning, drafting and editing stages of his writing

- used advanced facilities within the program to speed up the editing process and as a jotter while working.

Adobe Acrobat software:

- used this to download as much electronic information as possible so that he could use the 'find' feature to support his weak search skills and in accurate visual memory.

A Scanner:

Used this facility to support inefficient and time-consuming note-making;

Text-to-speech software:

Only started using this type of software towards the end of his studies to enable him to be more accurate in his proof-reading. 
- Spelling: ninth percentile (indicates that $91 \%$ of the population can perform more effectively).

- Reading: 16th percentile (this score represents low performance on single-word reading, especially for a university student; it also has an impact upon his speed of comprehension).

- Written production: 11 words per minute with an $11 \%$ error rate.

- One of Student B's greatest anxieties was being faced with a blank screen. $\mathrm{He}$ found this daunting and stultified his creativity:

It's daunting because you'll sit there looking at a white screen and how do you physically start?

He wanted to find a way of getting round this difficulty but always wanted to be in control, and therefore adopted a highly strategic approach to all his written assignments. He therefore used simple technology to enhance his functional writing:

- Word processing software.

- Adobe Acrobat software.

- A scanner.

- Blackboard information.

- Text-to-speech software (latterly).

He used a simple word-rich file, derived from a brainstorm. This gave him a global picture, which he needed to drive his activities. Having established a macro structure for his essay, he did a separate brainstorm for each of the components, breaking them down into simple bullet points. These became separate, small section notes. At this stage there was no sequence to the information yet he was conscious of the need to ensure that all the pieces of the jigsaw fitted together in a rational way. He regarded his 'brainstorm' as his 'working document', which he referred to at all times and which was frequently re-shaped as new information was found. This type of 'brainstorm' also helped him to break down his assignment into manageable parts, which he worked upon separately before bringing them all together in the translation and revision phases. In a sense he was compensating for memory capacity and storage deficits by ensuring that he did not overload his systems. Thus, each small section was treated as an ecosystem, which stood alone during the initial stages of formulation.

As a proficient user of Microsoft Office Professional, Student B worked with a split screen during drafting: in this way his small section notes could be displayed while he was elaborating the bullet points and generating prose. To ensure that he did not mix up the screens, he always used a specific background for his 'organiser' page. He was also fortunate in that his background had instilled in him a need for order, and his filing systems within the software were properly labelled and categorised effectively. He was also shown how to attach notes or audio triggers to phrases in his written work using more advanced facilities in Word. This meant that he could quickly 'jot' a reminder to himself, which was clearly marked on screen for him to work on at a later stage or to remind him to find some additional important information, which he had forgotten. 
He found that he could generate simple bullet points, which he could quickly rearrange into a structure. The threat of language production was minimised at this stage and allayed his fears of not being able to write a sentence. Thus, he found the blank page syndrome was no longer an issue because he was involved with the nuts and bolts of the information and content first and then moved on to the formulation of good construction later.

Collecting information for his essay was done electronically as far as possible. As a sophisticated user of technology, Student B's searching skills are advanced and, for example, he used the Adobe Acrobat 'find' facility to search for key words to compensate for his perceived hesitant reading skills. He preferred to access e-journals to save time on note-making. Like other dyslexic students, he copied chunks of text on-screen as part of his note-taking/making procedures because he found formulating language for his own notes time-consuming and laborious. E-journals allowed him to cut and paste information into his electronic files. He downloaded sections of course information displayed in Blackboard, thus using this mediated learning environment to his advantage. However, all of this was made more efficient because he had set up the electronic infrastructure for his essay sections in a complex filing system. He had recently started using TextHelp software to support his weak proof-reading skills. He explained that he could not spot his own errors, but if he had sections read out to him by the software he could more easily identify what needed to be changed. His draft copies also showed that he was able to use the spelling and grammar checkers to proof-read his work and to help him with editing.

\section{Student C: working memory difficulties and fear of plagiarism}

Student C was a dyslexic mother of two children. She was a mature student who had obtained her first degree in English and was currently on a postgraduate course. She had been aware of her dyslexic difficulties for many years but was not formally identified as dyslexic until the final year of her undergraduate studies. She had adopted a matter-of-fact approach to her problems and was a confident technology user. As a mature student who had achieved success before returning to study, she was aware of her weaknesses and in some cases had developed ways of compensating.

Table 3 provides an overview of the strengths and modes of working that were adopted by student $\mathrm{C}$.

Student C's basic skills were below the functional level expected for postgraduate study:

- Spelling: 10th percentile (indicates that $90 \%$ of the population can perform more effectively).

- Reading: 27th percentile.

- Written communication: 28.8 words per minute with a $7.6 \%$ error rate.

She was aware that her summary skills were weak: 
Table 3. Summary of strengths, technology and modal preferences of Student C

\begin{tabular}{|c|c|c|}
\hline Working styles & Strategies adopted & Technology use \\
\hline $\begin{array}{l}\text { Read far too much with no } \\
\text { strategy; }\end{array}$ & $\begin{array}{l}\text { Used intricate colour-coding } \\
\text { system for language on screen so }\end{array}$ & $\begin{array}{l}\text { Dragon Dictate Naturally } \\
\text { Speaking }\end{array}$ \\
\hline $\begin{array}{l}\text { Random approach to reading } \\
\text { resulting in this being an } \\
\text { overly long process; }\end{array}$ & $\begin{array}{l}\text { that she did not get confused and } \\
\text { to support weak working } \\
\text { memory capacity; }\end{array}$ & $\begin{array}{l}\text { Helps to get ideas quickly onto } \\
\text { screen for editing }\end{array}$ \\
\hline $\begin{array}{l}\text { Collection of information for } \\
\text { her essays is disorganised and } \\
\text { time-consuming; }\end{array}$ & $\begin{array}{l}\text { Used drafting to develop } \\
\text { conceptual knowledge; }\end{array}$ & $\begin{array}{l}\text { Kurzweil } \mathbf{3 0 0 0} \text { for read-back, } \\
\text { scanning text and combination } \\
\text { Supports hesitant and } \\
\text { inaccurate reading skills } \\
\text { Variable speed }\end{array}$ \\
\hline $\begin{array}{l}\text { Note-making is disorganised; } \\
\text { Long gestation period } \\
\text { needed to process after } \\
\text { collection; } \\
\text { Had to have global picture } \\
\text { before drafting; } \\
\text { Global picture needed to be } \\
\text { maintained during drafting } \\
\text { process to ensure that she } \\
\text { kept on task. }\end{array}$ & $\begin{array}{l}\text { Used mind-mapping, both } \\
\text { pencil and paper and } \\
\text { electronically, to help focus her } \\
\text { thoughts after her gestation } \\
\text { periods and to help to summarise } \\
\text { his thoughts; } \\
\text { Used peers as proof-readers. }\end{array}$ & $\begin{array}{l}\text { Inspiration } \\
\text { Schedule work plan } \\
\text { Quick overview }\end{array}$ \\
\hline
\end{tabular}

I think less words is harder. I have to go through the process of putting it all in and then taking it out!

Like many dyslexic writers, she had difficulty sequencing and clarifying her points:

Getting my ideas on paper is really difficult. I get stuck on things and they go round and round and round.

However, her most poignant comment was the following comment that encapsulates the feelings of many dyslexic writers who experience working memory difficulties that affect the ability to multi-task and whose low-level skill operation does not work on automatic pilot:

I have wonderful sentences in my head but to write means that I have to think about the shape of letters and the spelling. This slows me down considerably.

Student C freely admitted that a great weakness in her system was that she was disorganised with the note-making methods, and this often had a knock-on effect when translating and revising. The real-time writing sample and the writing log demonstrated that she spent a disproportionate amount of time in the drafting phase of writing her essay ( $46.85 \%$ of the total assignment writing time), closely followed by a lengthy editing period (32.43\% of the total assignment writing time). Both of these were the result of weak speed of language processing skills and fear of plagiarism, which results in checking and re-checking her sentences. The consequences of her weak working memory were compensated for by a variety of technological 
support. She realised that she needed to be able to get her ideas onto screen quickly before she forgot them. For this she used the speech recognition software, Dragon Dictate. In this way she was able to dictate her ideas straight onto screen from working memory. Once the information was on screen she then went about the translating and editing processes. Her hesitant decoding skills were enhanced by Kurzweil, a speech-activation system. Variable speed read-back was a vital feature for Student C, who could choose the speed to improve effective comprehension. She could slow down the speed when she came across scanned texts from chapters in books or ejournals if the subject matter was new or contained technical terminology she found difficult to remember. However, she found that, when using the facility to proof-read text, it was better to speed up the read-back facility to allow for chunks of information to be assimilated and heard.

Like Student A, Student C used Inspiration ${ }^{\circledR}$ to develop mind-maps to help her to get the global picture of the information contained in books or journal articles. This helped her to see 'how everything fits together', and helped her to overcome her difficulties in sequencing thoughts. Her lack of confidence in her writing ability was such that she always asked friends and family to check her work before she handed it in. She had noticed that even with spelling checkers and technological aids, mistakes in spelling, punctuation and sentence construction still occurred.

However, Student C's solution to plagiarism was simple and effective. She used colour-coded notes on screen to build up her written drafts:

- Green $=$ my notes.

- Black = text lifted from other sources.

- Red $=$ things to check before putting in the essay.

- Blue = my essay text.

By using colour on screen she was able to identify very quickly what was not her own language. She also used colour to give herself reminders of what she had to do.

\section{Implications for policy and practice}

The method and the results of these three case studies have implications for both policy and practice.

\section{Evidence-based planning of writing strategies}

The decision to use real-time sampling logs to monitor and record performance in the writing process was not taken lightly. Compared with other techniques such as Think Aloud protocols, Retrospective Reporting and Pause Analysis (Ericsson \& Simon, 1980; Hayes \& Flower, 1980; Hayes et al., 1987; Bereiter \& Scardamalia, 1987), realtime sampling data was objective and did not rely upon memory. Such data also provided detailed information about the specific aspects of the writing process, which caused the most difficulty to students and which turned out to be the most timeconsuming. All the information from the student logs was recorded and statistically 
analysed so that a graphical representation of performance of the different elements of the writing process was available.

Such data played a considerable part in the discussions with the students during de-briefing, and when helping the students to analyse the effectiveness of strategies and techniques. Each student was given a print-out of the performance analysis so that the researcher and the student could consider strategy application. All the students involved in the study were fascinated to see how much time they spent on different elements of the writing process. Although they were aware on a subconscious level of the impact of their dyslexia, to have hard evidence (the student's term) of what was going on was constructive. Such data could be useful for dyslexia support tutors:

- To provide an objective document that is non-judgemental as the basis for collaborative working.

- To provide an analysis of performance upon which future targeted support can be devised.

- Gaining an objective picture of how the student goes about the writing process is often difficult to obtain, particularly from dyslexic students who cannot remember what they have done. Such graphs can support working memory difficulties so that the student becomes aware of where strategies need to be applied.

These methods of data collection are not without their problems. The bleep was intrusive and may have resulted in a dip in concentration, which would have some effect upon the results. However, it was felt that weighing up all the effects, the data revealed a picture of the writer, which was used to improve the way in which he/she performs and ultimately to help each student to obtain better academic results.

Nevertheless, such a method could be used to improve all students' knowledge of their writing performance so that they could be aware of strengths and weaknesses and so increase potential performance during their time at university. Analysis of a whole cohort's writing performance during the process of writing one essay would also enable academic tutors to target curricular objectives to provide a more inclusive environment for development. This information could also be part of the Personal Development Profiles that are being used more extensively for student progression and development.

\section{Multi-modal uses of technology}

The three case studies illustrate how it is often the simple solutions that work. Nevertheless, it is also the flexibility of the use of technology and software that make the difference. In this way individualisation is the key to success. Using appropriate features of different software can ensure that the cognitive profile is matched accurately not only to the student's needs, but also to the demands of the course. Although the number of participants in the original study is small, patterns of working did emerge. In order to place working memory under less stress, working on small chunks 
of text and focused sections of a whole essay, using a variety of technological supports, increased the proficiency of the students' performance.

This has implications for future Disabled Students' Allowance packages, technology training for students and professional development for those who will be training students to use technology in the most effective way. Providing students with the full technology kit bag may not always be consistent with practical application. Some students may only need to learn how to use the advanced features of Word to provide the tools they need to communicate effectively. The Vygotskian model for the development of gradual student control relies upon the notion of students working along side an expert who can guide them in managing their own learning environment. This has implications for both assessment of need and specialist tutorial support.

The assessment of technology needs should be a multi-professional process not a linear, sequential procedure as is often the case at the moment. The specialist assessor and the specialist tutor must work in concert with technology specialists to determine the most effective technological scaffolds for each individual student. In this way, the dyslexic, cognitive profile can be matched to effective and efficient solutions. However, it is important to ensure that the tail does not wag the dog. At times the appeal of technology and its recognised capacity to provide support for writing can overshadow good sense (Sanderson, 1999). Stacey (1998, p. 72) pointed out that inappropriate technology provision could be just as negative as no provision:

A mismatch can hamper students' ability to use coping strategies to manage their dyslexia.

It must be remembered that at the heart of the student's academic experience is the curriculum. Acquiring the academic skills to function within this curriculum has long been the goal for tutorial support. Given that the notion of support 'embedded' in the subject curriculum is the model regarded as the most effective way of developing subject knowledge, inculcation into the academic community and academic skills, then assistive technology needs to be subsumed within this teaching model. Thus, technology skill acquisition should be driven by curriculum needs alongside developing communication skills. It may be that this multi-modal support should be coordinated by one tutor so that there is continuity for the student. This has implications for support structures and continuing professional development.

\section{References}

Baddeley, A. D. (1990) Human memory (Hove, Lawrence Erlbaum Associates).

Bereiter, C. \& Scardamalia, M. (1987) The psychology of written composition (Hillsdale, NJ: Lawrence Erlbaum Associates).

British Psychological Society (1999) Dyslexia, literacy and psychological assessment (Leicester, Division of Educational and Child Psychology of the British Psychological Society).

Britton, J. (1983) Shaping at the point of utterance, in: A. Freedman, I. Pringle \& J. Yalden (Eds) Learning to write: first language/second language (London, Longman). 
Bullock, R., Little, M. \& Millham, S. (1992) The relationship between quantitative and qualitative approaches in social policy research, in: J. Brannen (Ed.) Mixing methods: qualitative and quantitative research (Aldershot, Avebury).

Cohen, L. \& Manion, L. (1998) Research methods in education (London, Croom Helm).

Critchley, M. \& Critchley, E. R. (1978) Dyslexia defined (London, Heinemann).

DfES (2004) Removing barriers to achievement: the Government's strategy for SEN (London, Department for Education and Skills).

Ericsson, K. A. \& Simon, H. A. (1980) Verbal reports as data, Psychological Review, 87, 215-251.

Farmer, M., Riddick, B. \& Sterling, C. (2002) Dyslexia and inclusion (London, Whurr Publishers).

Frith, U. (1995) Dyslexia: can we have a shared theoretical framework?, fournal of Educational Psychology, 12, 6-17.

Hatcher, J. (2001) An evaluation of the types of provision for dyslexic students, paper presented at the 5th British Dyslexia Association International Conference, University of York.

Hayes, J. R. \& Flower, L. S. (1980) Identifying the organisation of the writing process, in: L. W. Gregg \& E. R. Steinberg (Eds) Cognitive processes in writing (Hillsdale, NJ, Lawrence Erlbaum Associates).

Hayes, J., Flower, L., Schriver, K., Stratman, J. \& Carey, L. (1987) Cognitive processes in revision, in: R. Sheldon (Ed.) Advances in applied psycholinguistics: Vol. 2 Reading, writing and language learning (Cambridge, Cambridge University Press), 176-240.

HMSO (2001) The Special Educational Needs and Disability Act. Available online at: http:// www.legislation.hmso.gov.uk/acts/acts2001/20010010.htm (accessed 5 October 2005).

Hinshelwood, J. (1917) Congenital word blindness (London, H.K. Lewis).

Hughes, C. A. \& Suritsky, S. K. (1994) Note-taking skills of university students with and without learning disabilities, Fournal of Learning Disabilities, 27(1), 20-24.

McLoughlin, D. (2001) Adult dyslexia: assessment, counselling and training, in: M. HunterCarsch \& M. Herrington (Eds) Dyslexia and effective learning in secondary and tertiary education (London, Whurr Publishers), 121-126.

McNaughton, D., Hughes, C. \& Clark, K. (1997) The effects of five proof-reading conditions on the spelling performance of college students with learning disabilities, fournal of Learning Disabilities, 30(6), 643-651.

Miles, T. R. (1982) Dyslexia: the pattern of difficulties (London, Granada).

Oshima, J. \& Oshima, R. (1999) Scaffolding for progressive discourse in CSILE: case study of undergraduate programs, paper presented at the Annual Meeting of the American Educational Research Association, Montreal.

Raskind, M. H. \& Higgins, E. L. (2003) Assistive technology for post-secondary students with learning disabilities: an overview, in: S. A. Vogel, G. Vogel, V. Sharoni \& O. Dahan (Eds) Learning disabilities in higher education and beyond: an international perspective (Baltimore, MD, York Press).

Reid, G. (2003) Dyslexia: a practitioner's handbook (3rd edn) (London, John Wiley and Sons).

Riddick, B., Sterling, C., Farmer, M. \& Morgan, S. (1999) Self-esteem and anxiety in the educational histories of adult dyslexic students, Dyslexia: An International fournal of Research and Practice, 5(4), 227-248.

Sanderson, A. H. (1999) Information technology and dyslexia: a case of 'horses for courses', paper presented at the Dyslexic learners: a holistic approach to support, De Montfort University, Leicester.

Scardamalia, M. \& Bereiter, C. (1996) Engaging students in a knowledge society, Educational Leadership, 54(3), 6-10.

Singleton, C. H. \& Aisbitt, J. (2001) A follow-up of the National Working Party survey of dyslexia provision in UK universities, paper presented at the 5th British Dyslexia Association International Conference, University of York.

Stacey, G. (1998) Equal opportunities and staff concerns, paper presented at the 2nd International Conference on Dyslexia in Higher Education, University of Plymouth.

Tharp, R. \& Gallimore, R. (1991) A theory of teaching as assisted performance, in: P. Light, S. Sheldon \& M. Woodhead (Eds) Learning to think (London, The Open University Press). 
Thomson, M. E. \& Watkins, E. J. (1998) Dyslexia: a teaching handbook (2nd edn) (London, Whurr Publishers).

Torrance, M. \& Jeffery, G. (Eds) (1999) The cognitive demands of writing: processing capacity and working memory effects in text production (Amsterdam, Amsterdam University Press).

Vygotsky, L. (1978) Mind in society (MA, Harvard University Press).

Yelland, N. \& Masters, J. (2005) Rethinking scaffolding in the information age, Computers and Education, in press. 